\title{
Figuras literarias en los titulares de la prensa costarricense
}

\author{
ANDREW SMITH \\ Escuela de Literatura y Ciencias del Lenguaje \\ Universidad Nacional \\ Escuela de Lenguas Modernas \\ Universidad de Costa Rica
}

\begin{abstract}
Resumen
Este artículo analiza titulares de periódicos costarricenses con la intención de explorar aspectos de la sociedad y la cultura nacionales. Este estudio muestra cómo las figuras literarias como metáforas, símiles, hipérboles y personificaciones son imágenes recurrentes en los periódicos costarricenses. Además, imágenes como la violencia y la guerra, la muerte, la comida, la destreza, la belleza, la comunicación, los animales y aun la mitología, son ideas comunes y recurrentes de los titulares de este país; por lo tanto, estos pueden ser una indicación importante de la sociedad y la cultura costarricenses.
\end{abstract}

Palabras claves: figuras literarias, titulares de prensa, prensa costarricense, cultura y sociedad

\begin{abstract}
This article analyzes headlines from Costa Rican newspapers with the intention of exploring aspects of Costa Rican society and culture. This study shows how figures of speech such as metaphors, similes, hyperboles and personifications are recurrent images in Costa Rican newspapers. In addition, the headlines used in this paper present a clear image of what is important or pertinent in Costa Rica. Images such as violence and war, death, food, skill, beauty, communication, animals, and even mythology are common and recurrent ideas that are seen in newspaper headlines from this country. For this reason, newspaper headlines are an interesting insight into Costa Rican society and culture.
\end{abstract}

Key words: literary figures, newspaper headlines, Costa Rican newspapers, culture and society 
L as figuras literarias son recurrentes en el lenguaje; como lo dice el crítico estadounidense Terry Eagleton quien afirma que "all language is in a way 'metaphorical"' (toda lengua es en cierta forma 'metafórica', Literary Theory an Introduction, 144). El lenguaje figurado se da cuando las palabras combinadas crean un significado no literal, es decir, un significado diferente del sentido propio de dichas palabras. Decir que alguien "canta como un pájaro", por ejemplo, es una forma elocuente de expresar que esa persona canta muy bien o bellamente. Aunque el lenguaje figurativo no es siempre fácil de definir, y es a menudo discutido y cuestionado como lo afirman Axelle Beth y Elsea Marpeau, también puede ser tan sencillo como decir "Tengo mil cosas que hacer" en lugar de decir "Tengo muchas cosas que hacer"; o decir "Él se nos fue" en lugar de decir "Él murió" (Figures de style, 5).

Los periódicos son, sin lugar a dudas, indicadores de aspectos culturales y sociales de un país o de una región. En los periódicos encontramos: estilos diferentes, lenguaje popular, sarcasmo, lenguaje formal, formas elípticas y humor (Culture Bound, 133). A esta lista se añaden imágenes literarias y lenguaje figurativo. Resulta entonces interesante observar cómo las figuras literarias del lenguaje abundan en los titulares de periódicos; probablemente por la simple razón de que llaman la atención del lector o lectora y así lo incitan a leer el artículo en su totalidad. Por consiguiente, un estudio y análisis del uso del lenguaje figurado y literario en los titulares de la prensa nacional pueden contribuir a "abrir la puerta" para apreciar gran parte de la cultura costarricense, pues como ya lo dijo Teun A. Van Dijk, "los usuarios del lenguaje hablan y comprenden no solo como personas sino como miembros de grupos" (El discurso como interacción en la sociedad, 64) y, definitivamente, los titulares de prensa reflejan esta perspectiva social. Para dicho estudio se tomarán ejemplos de titulares de diversos diarios costarricenses publicados en los meses de abril y mayo de 2012.

Sin lugar a dudas, una de las figuras literarias más recurrentes en los periódicos costarricenses es la metáfora, descripción de un objeto mediante la comparación con otro donde no existe entre estos una relación literal. La metáfora juega un papel preponderante en la prensa nacional. Para comenzar se puede citar el titular de La Nación (22 de abril, p. 24) en donde para referirse a los dos candidatos presidenciales de Francia se dice: "Sarkozy y Hollande se perfilan para su duelo final en mayo-El mismo capitán o un golpe de timón: la apuesta para Francia”. El titular es rico en lenguaje figurativo, pues la campaña presidencial se presenta como un duelo y los dos candidatos entonces recurren a las armas: Francia es un barco y el presidente electo será su capitán. Si Zarkozy pierde (lo cual ya ocurrió) el golpe de timón representará un gran giro para la política francesa, debido a la elección de un nuevo presidente. La apuesta, llevada a cabo por los votantes franceses, implica que la decisión de la mayoría no se visualiza como algo seguro, pues al apostar se puede ganar o también perder. Incluso en la redacción de este mismo titular, no queda claro si el riesgo está en dejar a Sarkozy o en reemplazarlo por Hollande, o en ambas posibilidades. Además, un barco es un medio de transporte que puede ser considerado un vehículo de guerra o un vehículo de recreación o placer. 
En el mismo periódico nacional (La Nación, 22 de abril, p. 25-A), siempre en torno del tema de la elección presidencial en Francia, otro titular dice: "Candidatos velan armas en vísperas de comicios". Sin duda con la imagen de las armas, la elección se visualiza como una batalla. Además, esta percepción de la prensa nacional de relacionar la política con la violencia, no se limita a Francia o a Europa, pues otra vez La Nación (5 de mayo, p. 32-A) describe la campaña presidencial de los Estados Unidos de la siguiente manera: "Campaña de Obama afila armas contra Rommey". En otras palabras, desde una perspectiva nacional, las armas se protegen y se preparan para las campañas presidenciales en dos países extranjeros bastante poderosos.

Sin embargo, varias de las metáforas que se encuentran en los titulares de la prensa costarricense se relacionan directamente con imágenes bélicas o de violencia. La guerra siempre ha sido, tristemente, parte de la humanidad. Además, la idea de muerte y destrucción siempre está presente en toda sociedad, incluso en países que no están en guerra, como Costa Rica. Pero a veces, la imagen de guerra se distorsiona como lo hace Hollywood, pues la glorifica y exalta, y la prensa, ya sea nacional o internacional, también contribuye a esta distorsión. El New York Times, por ejemplo, al reportar el ataque talibán de las Torres Gemelas en 2001, utilizó el siguiente titular: "A Nation Challenged", es decir, "Una nación desafiada". Un desafío puede ser considerado algo positivo, y esto alude la idea de ataque. Además, un desafío implica una respuesta. De esta forma, la idea de violencia y guerra es reemplazada al usar una metáfora que conlleva a la competencia (Sontag, Regarding the Pain of Others, 8).

La violencia también se manifiesta en los titulares de prensa referentes a nuestra nación. En el Diario Extra (5 de mayo, p. 22), vemos una metáfora bastante violenta relacionada con el campo deportivo. Al informar sobre Alexander Guimaraes y su trabajo como entrenador del equipo Saprissa, el diario en un titular afirma: "Guima” se juega la cabeza en el Nacional”. El despido del entrenador se compara con la decapitación, puesto que este no solo pierde su trabajo, sino su "cabeza". Pareciera que a diferencia de las percepciones de la prensa nacional sobre otros países, la pasión de los costarricenses no se ve tanto en los titulares del campo político como en los del ámbito deportivo.

Así, en la política nacional predominan más bien las metáforas alusivas a la muerte. Un ejemplo lo encontramos en la primera plana de La Nación del 23 de abril que dice: "Gobierno da por sepultado el plan fiscal". Otro ejemplo similar lo encontramos en La Teja (5 de mayo, p. 13) que dice: "Doña Laura fumiga al (ministro) del MOPT". En esta metáfora, la Presidente de la República se deshace de las plagas al "fumigar", es decir, destituir al funcionario público, según el artículo, por su falta de responsabilidad al permitir actos de corrupción. Siguiendo con la propuesta comparativa de esta metáfora, el ministro se convierte en una imagen kafkiana de insecto que debe ser eliminado.

Pero en el campo deportivo, además de la violencia anteriormente mencionada, se pueden observar en los titulares, metáforas que aluden a diversas acciones o destrezas. El periódico Al Día (4 de mayo, p. 24) al hacer un reportaje sobre el equipo profesional de baloncesto llamado Miami Heat, el cual ganó un 
importante partido, presenta el siguiente titular: "Heat cocinó la serie". Así, el evento deportivo evoca el arte de cocinar, además del juego de palabra que suscita y ofrece el propio nombre del equipo estadounidense, Heat, es decir, calor y de cómo éste completa la acción de cocinar. El mismo diario nacional (Al Día, 5 de mayo, p. 40) utiliza otra metáfora para describir la estrategia o habilidad de un equipo de futbol costarricense al emitir el siguiente titular: "Saprissa va esta noche a darle el mate a los Guapileños". Es interesante observar cómo a través de esta metáfora, el partido de futbol pasa a ser comparado con un partido de ajedrez. Además, con esta comparación, se hace alarde del poder intelectual más que de la destreza física para obtener la victoria. Así, el equipo Saprissa es visto como el jugador de ajedrez que sabe mover sus piezas con muy buena estrategia. Otro ejemplo en el mismo periódico (Al Día, 5 de mayo, p. 26) se observa al describir la destreza de un lanzador de beisbol de las grandes ligas al decir: "Weaver lanzó una joyita”. Siguiendo la metáfora, el lanzador hizo un juego perfecto en que ningún rival pudo llegar a primera base, lo cual es representado en la comparación de sus acciones con una joya, preciosa y valiosa a la vez.

Siempre dentro del campo deportivo, los titulares presentan lenguaje figurativo bastante atractivo para el lector. En el diario Al Día (5 de mayo 2012, p. 16), se publica el siguiente titular: "La pelea del año—Saldrán chispas de sus puños. Cotto contra Mayweather: hoy toca hablar con golpes en el ring". El boxeo profesional es un deporte bastante violento que ha causado heridas muy serias e incluso varias muertes a los pugilistas. Pero en este titular, el boxeo aparece como algo eléctrico, grandioso o mágico si se quiere, pues de los puños salen "chispas", en lugar de sangre, que sería lo más realista. Aquí los boxeadores no se hieren, sino se comunican pues "hablan con golpes" y entonces la brutalidad de los golpes se compara con el acto diplomático de hablar. Además, los dos boxeadores adquieren la dimensión de dos colosos. Sin haber leído el artículo, ya los pugilistas han sido engrandecidos desde el titular.

Definitivamente, dentro del campo deportivo en la prensa de Costa Rica, se destaca el lenguaje figurativo en los titulares relacionados con el futbol. En éste, las imágenes de animales se personifican y se palpa cómo las mascotas de los principales equipos incluso se glorifican. Al Día (5 de abril, p. 6) describe a la mascota de la Liga Deportiva Alajuelense en un titular como: "El león de las siete vidas". Es interesante ver cómo en lugar del gato típico del refrán popular que está provisto de siete vidas, este león adquiere dotes de inmortalidad y, por lo tanto, no sólo es personificado sino casi inmortalizado al no ser eliminado (al menos a esa fecha) del campeonato nacional. El mismo diario, ese día en su primera plana, evoca una vez más el mundo animal al expresar: "Liga pide cerrar la "Cueva" morada". En esta metáfora el estadio del Saprissa es comparado con una cueva, que es a su vez la morada del monstruo o dragón, mascota de dicho equipo.

Otras metáforas, siempre dentro del campo deportivo, muestran la diversidad agrícola de Costa Rica. Ciertos cultivos o productos son propios de ciertas regiones del país; esto es utilizado en la jerga deportiva y se refleja en los titulares de la prensa nacional. Como ilustración del punto anterior, el Diario Extra 
(5 de mayo, p. 24) al informar que un jugador de futbol del equipo Puntarenas es transferido o comprado por el equipo de Alajuela, publica el siguiente titular: "Comerá mangos en lugar de chucheca", palabras que hacen alusión a la gran producción de mangos en la provincia de Alajuela y a la popularidad de los mariscos, específicamente las chuchecas, en el puerto de Puntarenas; la metáfora se construye basándose en esos aspectos.

Además de cultivos o productos típicos de determinadas zonas del territorio nacional, metáforas que utilizan recursos naturales aparecen en forma recurrente en los titulares de los diarios costarricenses. El agua, por ejemplo, es una imagen que se destaca. En La Nación (15 de abril, sección Áncora, p. 3) al hablar sobre diseños arquitectónicos, se escribe el siguiente titular: "Una celebración que fluye". En este sentido, el verbo fluir, asociado con el movimiento constante del agua, ayuda a representar la imagen estética y de movimiento de los edificios. En el periódico Semanario Universidad (28 de marzo-10 de abril, sección Forja, p. 2-3) aparece el titular: "Constantino Láscaris, Costa Rica: nombres que se lleva el río". Aquí el fluir del agua se asocia con la imagen del tiempo y sirve para describir el impacto de la importante obra de este gran erudito español que vivió en nuestro país. En La Nación (23 de abril, sección Viva, p. 7) aparece otro titular con una metáfora relacionada con el agua al decir: "Cuando la danza hace que lluevan aplausos". En otras palabras, aquí la imagen del agua, más concretamente la imagen de la lluvia, en sentido metafórico, proporciona fuerza a la admiración y apreciación del público ante la belleza del espectáculo y provoca la lluvia de aplausos del público. En suma, las metáforas del agua brindan movimiento, tiempo, vida y fuerza a los titulares de los diarios nacionales.

Algunas de las metáforas de los titulares son bastante literarias, sobre todo las relacionadas con el campo artístico y esto las hace, en cierta forma, más atrayentes para el lector. Al Día (4 de mayo, p. 36-37) presenta un titular en que el cantante español Julio Iglesias habla sobre su esposa al expresar: "Mi mujer son mis alas". El caso presenta un tipo de sinécdoque muy interesante, pues la comparación radica en que el cantante se iguala a un ave cuya mujer es una parte de él, las alas, elemento importante que lo hace volar. En otras palabras, el cantante español expresa que su esposa es la razón de su éxito, siguiendo así la perspectiva del refrán, un tanto patriarcal, que dice que "detrás de un gran hombre, hay una gran mujer". Otro ejemplo similar se observa en el periódico mensual Campus de la Universidad Nacional (mayo, p. 13) que presenta el siguiente titular: "El perfume de la poesía". La figura literaria evoca la combinación de imágenes sensoriales, en este caso el aroma del perfume, con los sonidos o melodía de la poesía. De esta forma, la belleza de la poesía es resaltada a partir de los sentidos, como lo hicieron los poetas simbolistas franceses del siglo XIX. Podría ser también considerada como una personificación si se compara el género literario lírico con una mujer portadora de perfume. Otro ejemplo asociado con el campo artístico, más específicamente el musical, es el titular que presenta La Nación (25 de abril, sección Viva, p. 8) que dice: "Roquero tiende su mano a los sueños de los más pequeños". La rima y musicalidad del titular mismo, junto con la imagen del cantante tendiendo su mano para 
ayudar a los más pequeños, nos recuerda un poco la figura de Miguel Ángel en la pintura de la creación de Adán, donde se representa a Dios extendiendo su mano para crear a la humanidad. En otras palabras, con este titular bastante figurativo, se destaca la imagen del roquero protegiendo a los niños y ayudándolos a lograr sus sueños.

Junto con las metáforas están los símiles, otro tipo de comparación más clara por el uso de palabras comparativas, que también están presentes en los titulares de la prensa costarricense. Al Día (4 de mayo, p. 19) nos presenta un claro ejemplo con su titular: "Celebraron como los dioses". Aquí se describe la celebración de victoria del equipo español de futbol Real Madrid. Pareciera que la intención del titular es transmitir la idea de que los simples mortales no pueden festejar como las deidades míticas. La misma idea se encuentra en otro diario nacional de ese mismo día, pues La República (4 de mayo, p. 35) al reportar la misma celebración dice en su titular: "La Diosa canta de nuevo". Otra vez el equipo campeón del futbol español es comparado con una deidad, quien en esta ocasión incluso canta su victoria. ¡Qué mejor celebración se puede tener que una en que una diosa cante!

Las hipérboles son también parte del repertorio de los titulares de la prensa nacional y muestran una gran diversidad. A continuación se presentan dos de ellas a manera de ilustración. La primera salió en La Prensa Libre (4 de mayo, sección AS, p. 8) y dice: "Juan Diego Ramos vive un viaje eterno en su bicicleta". La segunda apareció en La Nación (5 de mayo, sección Viva, p. 18) y dice: "Gwen Stefani se divide en mil partes para ser buena madre". Los dos titulares brindan nombres específicos, el primero es el de un fotógrafo profesional que expone retratos de bicicletas y el segundo presenta el nombre de una famosa actriz. Los dos, tanto Ramos como Stefani, parecen realizar acciones denegadas a la raza humana: Ramos no puede tener un viaje eterno en bicicleta y Stefani no puede dividirse en mil partes para hacer las muchas funciones que ella cree constituyen el quehacer de una buena madre. Es interesante ver cómo trabaja la hipérbole en forma diferente desde una perspectiva de género. Aunque las dos personas mencionadas son profesionales, para el hombre la hipérbole se desarrolla en su campo profesional, para la mujer se da en su rol materno. La hipérbole también señala el sacrificio de la mujer en el ámbito familiar y hace alusión a su ardua labor como madre.

Las personificaciones no podían faltar dentro del repertorio de los titulares de la prensa nacional. Un titular de La Nación (25 de abril, p. 30-A) dice: "Una ley sin pies ni cabeza". La personificación es clara y también lo es la crítica social implícita en esa personificación contra el sistema judicial. Si la ley no tiene ni pies ni cabeza, entonces carece de apoyo y de sentido y por lo tanto no podrá mantenerse o acatarse. Además, La Nación (23 de marzo, p. 16) presenta otro ejemplo claro de personificación al afirmar en un titular: "Quesos maduros: El mejor amigo del vino". Definitivamente, el vino y el queso van de la mano al combinarlos en el paladar, pero de eso a decir que son mejores amigos es atribuirles características humanas. También Al Día presenta una muy interesante personificación (5 de mayo, p.16) al decir en un titular: "Museo más vivo que nunca". 
Primero el museo pasa de ser un edificio inerte que guarda objetos del pasado a un ser viviente que a la vez hace que el pasado se haga presente. Por lo tanto, en esta personificación el museo cobra vida y también en cierta forma ocurre con los objetos o exposiciones que se encuentran en él.

Y lo contrario de la personificación, es decir la objetivación, también se visualiza en los titulares de la prensa nacional. El ejemplo claro lo presenta $L a$ Prensa Libre (4 de mayo, sección AS, p. 8) en donde se publica un titular que dice: "Barbie Humana genera polémica". El artículo trata de una mujer rusa quien clama ser la versión humana de la conocida muñeca americana. Para lograr esta transformación, la mujer se ha sometido a cirugía estética, ha utilizado mucho maquillaje, ha adquirido un nuevo guardarropa y ha hecho todo lo posible para ser la Barbie humana. La pregunta que genera la polémica es bastante pertinente: ¿Está siendo la muñeca Barbie personificada por las acciones de esta mujer o está siendo la mujer misma objetivizada o cosificada al tratar de convertirse en una Barbie? Lo más patético es que no es la sociedad patriarcal quien la objetiviza sino es decisión de la mujer misma al seguir, obviamente, una perspectiva patriarcal de belleza y aceptación social.

La lista de ejemplos de lenguaje figurado o literario es interminable en los titulares de la prensa nacional. Como lo dijeron Axelle Beth y Elsea Marpeau, "Une des caractéristiques du langage humain est sa capacité à s'autoinventer ..." (Una de las características del lenguaje humano es su capacidad de autoinventarse, Figures de style, 5), y en el lenguaje literario esta capacidad es aún más elocuente. Sin duda, el tema merece un estudio más extenso por el potencial que genera. Se podría clasificar un corpus según su uso, el periódico que lo utiliza, el tipo de noticia que lo presenta o la sección en que éste se encuentra ubicado. Por ahora, es bueno explorar no tanto el uso y el tipo de noticia que genera el titular sino la intención al usarlo.

Se podría hablar entonces de manipulación textual, al hacer uso de un lenguaje cuyo fin es atraer a los lectores y lectoras e inducirlos/las a leer todo el artículo. Pero ¿qué es en sí lo atrayente: la sonoridad de las palabras, las imágenes que se evocan, o las sensaciones que éstas suscitan en el lector o lectora? Podría ser una combinación de todo lo anterior, si nos ponemos a pensar en lo que cada figura crea. Dedre Gentner ha dicho que el proceso de "extracting relations via analogy and then preserving them via language acts to bootstrap learning and to create the structured symbolic representations" (lograr relaciones por medio de la analogía y después mantenerlas mediante los actos de lenguaje para facilitar el aprendizaje y crear representaciones simbólicas estructuradas, Language in Mind, 228) y las metáforas crean este tipo de relaciones. En realidad, las metáforas asocian cosas que en otro contexto resultaría imposible relacionar y, por lo tanto, permiten la transferencia de ciertas cualidades que en otro contexto serían difíciles de trasladar. Los símiles hacen que estas comparaciones tengan nexos más estrechos; las hipérboles permiten el uso exagerado de la imaginación; las personificaciones son, si se quiere, transformaciones mágicas del mundo animal al humano. En fin, todo lo anterior se podría limitar al poder de la palabra y al impacto del discurso como fenómeno práctico y cultural. 
Ya grandes literatos como Neruda y Cortázar habían señalado el valor de la metáfora, por ejemplo. También importantes lingüistas habían estudiado el alcance y los efectos socioculturales del lenguaje figurado en el individuo como en la sociedad. El presente artículo permite visualizar ciertos rasgos culturales de los costarricenses mediante la construcción de titulares de prensa. En la sociedad o ámbito nacional parece que se visualiza más pasión en el deporte que en la política. Si se hace un conteo de los ejemplos proporcionados, es el futbol el deporte que presenta el ámbito más utilizado. Para llamar la atención del "tico" (costarricense) se utiliza el lenguaje figurado partiendo de íconos o productos que evoquen valores nacionales. A veces no hay diferencia ni jerarquías, pues se colocan en un mismo nivel mascotas deportivas, a altos funcionarios gubernamentales, a figuras populares o a grandes líderes mundiales. La realidad nacional se impone en muchas de las imágenes que invocan los titulares de la prensa nacional y algunas veces se presenta un doble estándar de una misma situación según el lugar en que ésta acontece. Se vislumbran diferencias sociales, de género y de tipo económico según la noticia y la intención de su titular en el lector. Como se dijo antes, el tema de los titulares de la prensa nacional es amplio y bastante enriquecedor para futuras investigaciones lingüísticas, sociológicas, literarias, en fin, un tema muy pertinente para ser desarrollado dentro de un marco sociocultural.

\section{Bibliografía}

Beth, Axelle and Elsa Marpeau. Figures de style. Paris: Librio Inédit, 2005.

Eagleton, Terry. Literary Theory: An Introduction. Minneapolis: Minnesota Press, 1983.

Gentner, Dedre and Susan Goldin-Meadow, eds. Language in Mind: Advances in the Study of Language and Thought. Cambridge: The MIT Press, 2003.

Griswold, Wendy. Cultures and Societies in a Changing World. Los Angeles: SAGE Publications Inc, 2013.

Iser, Wolfgang. The Implied Reader. Baltimore: The John Hopkins University Press, 1974.

Láscaris, Constantino. El costarricense. San José: EDUCA, 1985.

Sontag, Susan. Regarding the Pain of Others. New York. Farrar, Strauss and Giroux, 2002.

Valdes, Joyce Merrill. Culture Bound. New York: Cambridge University Press, 1986.

Van Dijk, Teun A. El discurso como interacción social. Barcelona: Gedisa, 2000. 